\title{
A new assessment of the elastic thickness (Te) structure of the Indian shield, and its implications
}

\author{
Deshraj Trivedi ${ }^{1}$, Yudhvir Singh ${ }^{2}$, Tanmay K. Maji ${ }^{1}$, Suresh Ch. Kandpal ${ }^{1}$, Rajesh R. Nair ${ }^{2,{ }^{\star}}$ \\ ${ }^{1}$ IIT Kharagpur, Department of Geology and Geophysics, Kharagpur, India \\ ${ }^{2}$ IIT Madras, Department of Ocean Engineering, Madras, India
}

\section{Article history}

Received May 19, 2011; accepted January 25, 2012.

Subject classification:

Elastic thickness, Indian shield, Seismic zoning, Himalayas.

\begin{abstract}
The elastic thickness (Te) of continents is a matter of much debate. Recent studies have shown that a number of factors control the continental Te, including age, heat flow, and lithospheric thickness. Here, we estimate the Te structure of the whole Indian shield using an improved isotropic fan wavelet land ocean deconvolution methodology, and we compare these results with the global published Te estimates in the Archean, Proterozoic and younger geological provinces. Our study reveals low (0-45 km/0-35 $\mathrm{km})$, intermediate $(45-70 \mathrm{~km})$ and high $(70-100 \mathrm{~km})$ Te values in the Archean/Quaternary, the Proterozoic, and the Tertiary provinces, respectively, of the Indian shield. This is in contrast with global estimates of Te in similar geological provinces. In the absence of any correlation of Te with any controlling parameters, we propose that the mantle properties, rather than the tectonic history, are responsible for influences on the Te values within the Indian shield. The global positioning system horizontal velocity vectors yielded a locking depth of ca. $20 \pm 4 \mathrm{~km}$, and the aseismic creep beyond correlates well with the high strength of ca. $70 \mathrm{~km}$ to $100 \mathrm{~km}$ in the central Himalayan foreland.
\end{abstract}

\section{Introduction}

Although different methods yield different absolute values, it has been convincingly shown that the elastic thickness (Te) in cratons is always controlled by age and heat flow [PérezGussinyé and Watts 2005, Simons et al. 2000]. Several studyies have suggested that the Te of continents cannot be described by any relationship with only a single parameter [Watts and Burov 2003, McNutt et al. 1988, Watts 1992].

Earlier investigations around the globe using spectral analysis have suggested that the Te of cratonic regions is greater than ca. $60 \mathrm{~km}$; e.g., for Africa [Djomani et al. 1995], South America [Pérez-Gussinyé et al. 2009], Canada [Wang and Mareschal 1999], and Australia [Simons et al. 2000]. Recently, it was argued that the recovery of high Te values is dependent on the window sizes [Pérez-Gussinyé and Watts 2005]. Using several window sizes, as $400 \mathrm{~km}^{2} \times 400 \mathrm{~km}^{2}$, $600 \mathrm{~km}^{2} \times 600 \mathrm{~km}^{2}, 800 \mathrm{~km}^{2} \times 800 \mathrm{~km}^{2}$ and $1,000 \mathrm{~km}^{2} \times$
$1,000 \mathrm{~km}^{2}$, Pérez-Gussinyé and Watts [2005] showed that smaller window sizes improve the resolution, but may not be large enough to recover the maximum value of Te.

The first attempts to estimate the Te in the Indian craton were made by Karner and Watts [1983] and LyonCaen and Molnar [1985]. Using forward modeling between the Bouguer anomaly and the topography they obtained Te values of $80 \mathrm{~km}$ to $110 \mathrm{~km}$ in the Ganges basin. Free-air admittance by McKenzie and Fairhead [1997] yielded the lower Te value of $24 \mathrm{~km}$, which was found to be correlated with seismogenic thickness (Ts). However, subsequent studies by Handy and Brun [2003] suggested that the Te can easily exceed the Ts as well. Using multitaper spectral analysis, Rajesh et al. [2003] characterized the relative variations in the Te in the India-Eurasia collision zones. In another analysis, Rajesh and Mishra [2004] used the transitional coherence wavelength to characterize the tectonic provinces. Jordan and Watts [2005] used both forward and inverse flexural and gravity modeling techniques, and they obtained spatially varying Te structures that varied from $0 \mathrm{~km}$ to $125 \mathrm{~km}$ in the India-Eurasia collision zones. However, none of these studies could demonstrate any convincing correlations between the Te values and any of the controlling parameters, such as age and temperature. One possible reason for this might be that most of the forward modeling techniques were only along some one-dimensional profiles, and hence they failed to capture the spatial variation of the Te. Hence, a reappraisal of the spatial variation of the Te with an improved methodology would add new dimensions to the study of the lithospheric strength within the Indian shield.

Recent studies have shown that the fan wavelet method has been relatively successful in deriving the Te structure in continental areas; e.g., in the Australian shield [Kirby and Swain 2011], the Canadian shield [Audet and Mareschal 2004], and the South American shield [Tassara et al. 2007]. Highresolution, spatially varying Te maps can resolve regional 


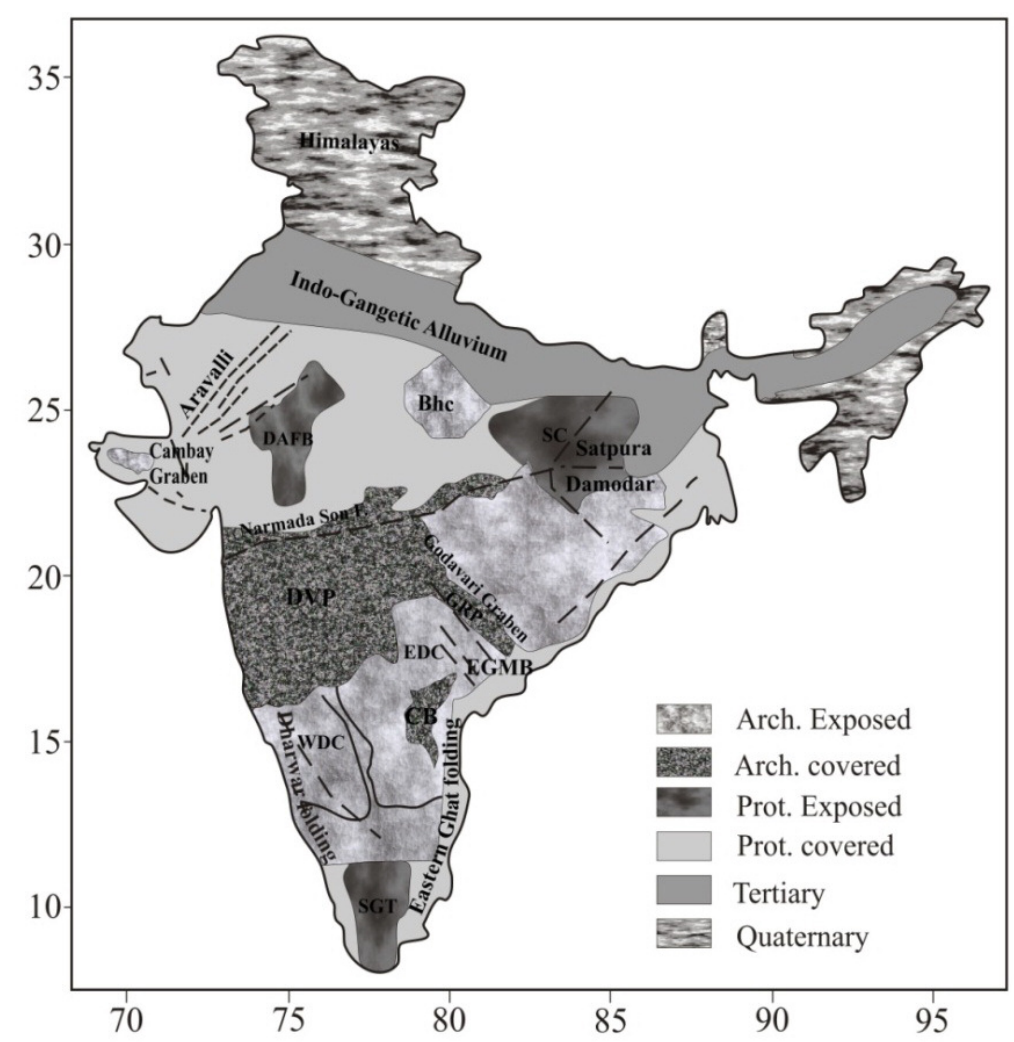

Figure 1. Geotectonic map of the whole Indian shield, indicating the ages of the different zones. The map is modified after Rajesh and Mishra [2004]. Abbreviations: BC, Bhandara craton; Bhc, Bundelkhand complex; CB, Cudappah Basin; DAFB, Delhi Aravalli fold belt; DVP, Deccan volcanic province; EDC, Eastern Dharwar craton; EGMB, Eastern Ghat Mountain belt; GRP, Godavari Rift province; SC, Singbhum craton; SGT, Southern Granulite Terrain; WDC, Western Dharwar craton.

scale features that can be correlated to surface geological structures. In the present study, we look at the discrepancies in the estimation of the Te within the Indian shield using the isotropic fan wavelet, which uses large window sizes and estimates the Te by merging the databases of the land [Rajesh et al. 2003, Rajesh and Mishra 2004] and the ocean [Anderson and Knudsen 1998, Anderson et al. 2008].

\section{The tectonic settings}

The Indian subcontinent has a complex geological and tectonic setting that consists of Precambrian cratons of Archean age and rift zones filled with Proterozoic and Phanerozoic sediments [e.g. Biswas 1999]. A geological map of the whole Indian shield, along with the major tectonic features, is shown in Figure 1. The geological structure of the Indian shield can be subdivided into three main units [Krishnan 2006]:

(a) The Himalayan front in the north, which results from the Mesozoic subduction and the collision between the Indian and Eurasian plates.

(b) The Indo-Gangetic plains, which are located between the abruptly rising Himalayas in the north and the Indian peninsula in the south, and which extend from east to west.

(c) The Indian peninsula in the south, which comprises the Indian shield with the Deccan traps and the Dharwar cratons.
The Precambrian rock in India [e.g. Naqvi 2005, Sharma 2009] is subdivided into two categories: the Archean system, and the Dharwar system. The Archean rock is mainly found in the Dharwar, Singbhum, Bundelkhand, and Bastar cratons. The Aravalli and Eastern Ghat cratons are of late Proterozoic age. The Indo-Gangetic plains are mostly filled with Quaternary sediments that come from the erosion of the Himalayas [e.g. Bir Singh 1996]. An important feature in the southern Indian peninsula, the Deccan traps, evolved as flood basalts in the late Mesozoic and early Tertiary period. The origin of these traps is still not unanimous; hot-spot volcanism and mantle plumes are the most discussed theories at present [e.g. Sen 2001, Sheth 2007].

\section{The data}

The topography, bathymetry and Bouguer anomaly data are shown in Figure 2. The bathymetry data were extracted from the Digital Atlas of the General Bathymetric Chart of the Oceans (GEBCO; http://www.gebco.net/), which was published by the British Oceanographic Data Centre on behalf of the International Oceanographic Commission of UNESCO (http:/ / ioc-unesco.org/) and the International Hydrographic Organization (http:/ / www.iho. int/srv1/). The GEBCO data were made available by the National Oceanic and Atmospheric Administration [2003]. We merged the gravity data for the land and the ocean 

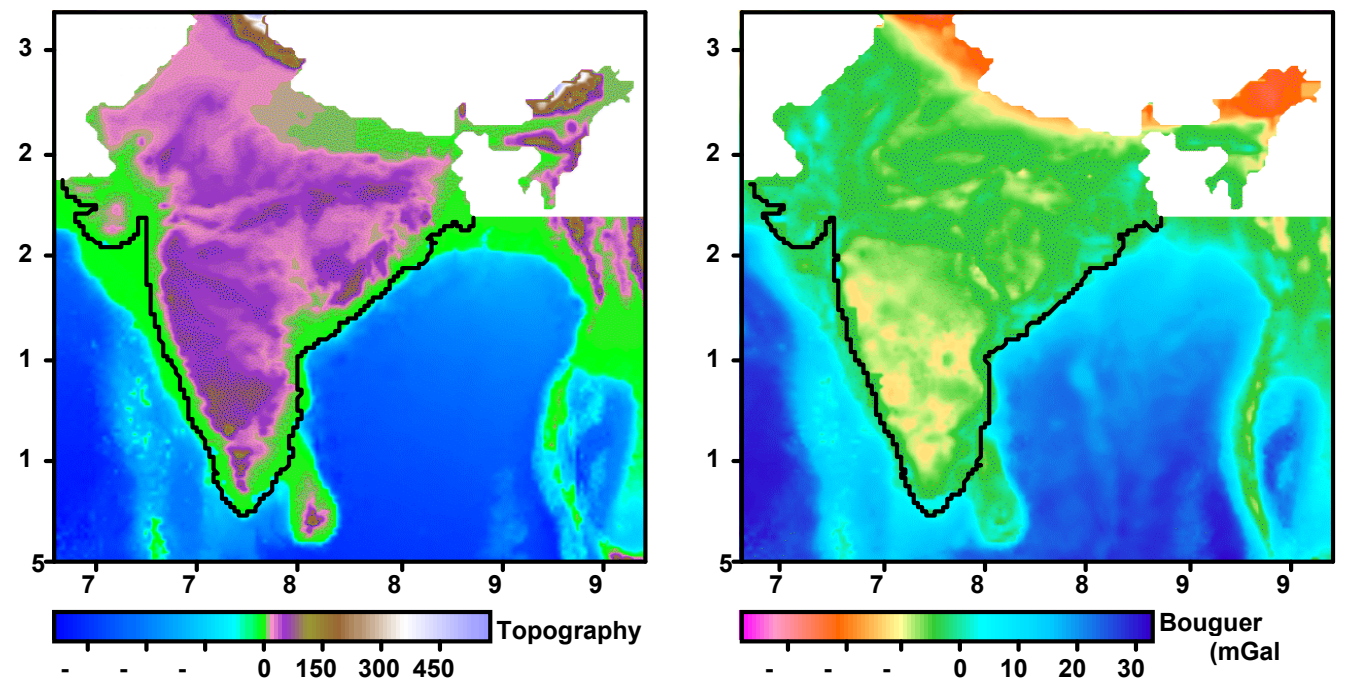

Figure 2. The Indian shield and the adjoining oceanic regions. (a) Topography. (b) Bouguer anomaly.

using the land-ocean deconvolution scheme. The gravity and topography data source for the land is the same as that used by Rajesh et al. [2003], Rajesh and Mishra [2004], and Rajesh [2004]. The cumulative error in the Bouguer gravity field including the errors in the elevation is estimated to be $1 \mathrm{mGal}$ to $2 \mathrm{mGal}$ [Rajesh and Mishra 2004]. The free-air anomaly data for the oceanic regions come from the global marine gravity field from the ERS-1 and GEOSAT geodetic mission altimetry of Anderson and Knudsen [1998] and Anderson et al. [2008]. The marine free-air gravity anomaly data, $\Delta \mathrm{G}_{\mathrm{f}}$, is converted to the Bouguer gravity anomaly, $\Delta \mathrm{G}_{\mathrm{b}}$, using the formula:

$$
\Delta \mathrm{G}_{\mathrm{b}}=\Delta \mathrm{G}_{\mathrm{f}}+2 \pi \Delta \rho \mathrm{GH}
$$

where $\Delta \rho=1,820 \mathrm{~kg} \cdot \mathrm{m}^{-3}$ is the density contrast between the surface rock and the water, $\mathrm{H}$ is the bathymetry (in $\mathrm{m}$ ), and $\mathrm{G}$ is the gravitational constant. The crustal thickness data used was taken from the CRUST 2 model [Bassin et al. 2000].

\section{Methodology}

The fan wavelet technique [Kirby and Swain 2004, Audet and Mareschal 2007, Kirby and Swain 2011] uses the superposition of the rotated two-dimensional (2D) Morlet wavelets arranged in a 'fan' geometry to obtain the wavelet coherence or admittance, by computing the co-spectra and cross-spectra of the gravity and topography data.

The continuous wavelet transform of a $2 \mathrm{D}$ spatially distributed signal $\mathrm{g}(\mathrm{x})$ is estimated by taking the convolution of the signal with the complex conjugate of a wavelet, given by:

$$
\tilde{g}(s, x, \theta)=F^{-1}\left\{\hat{g}(k) \widehat{\psi}_{s, \theta}^{*}(k)\right\}
$$

where $\tilde{g}(s, \boldsymbol{x}, \theta)$ is the complex wavelet coefficient, $s$ is the width of the wavelet, $\theta$ is the rotation parameter, $k$ is the $2 \mathrm{D}$ wavenumber, $F^{-1}$ is the inverse $2 \mathrm{D}$ Fourier transform, $\hat{g}(\boldsymbol{k})$ is the 2D Fourier transform of the signal $g(x), \widehat{\psi}_{s, \theta}^{*}(k)$ is the complex conjugate of $\widehat{\psi}_{s, \theta}(k)$, where:

$$
\widehat{\psi}_{s, \theta}^{*}(k)=s \widehat{\psi}\left(s \Omega^{-1}(\theta) k\right)
$$

is the $2 \mathrm{D}$ Fourier transform of the 'daughter' wavelets derived by dilating, translating and rotating the mother wavelet, and $\Omega(\theta)$ is the rotation matrix. For the calculation of isotropic coherence function, the wavelet coefficients $\tilde{g}(s, \boldsymbol{x}, \theta)$ must be complex quantities. The problem with real wavelets is that they are not complex, although they are isotropic, whereas complex wavelets are not in general isotropic. To overcome this problem, superposition of Morlet wavelets is used, which produces isotropic and complex wavelet coefficients. The $2 \mathrm{D}$ wavelet coherence can then be estimated by summing the wavelet co-spectra and cross-spectra over different azimuths:

$$
\gamma_{W}^{2}(s, \boldsymbol{x})=\frac{\left\lfloor\left(\tilde{g}_{s x \theta} \tilde{h}_{s x \theta}\right)_{\theta}\right\rfloor^{2}}{\left(\tilde{g}_{s x \theta} \tilde{g}_{s x \theta}^{*}\right)_{\theta}\left(\tilde{h}_{s x \theta} \tilde{h}_{s x \theta}^{*}\right)_{\theta}}
$$

where $\tilde{g}_{s x \theta}$ and $\tilde{h}_{s x \theta}$ are the complex wavelet coefficients of the Bouguer anomaly and topography, respectively.

The wavelet method has advantages over the windowed Fourier transform method, such as the multitaper method, because unlike the windowed Fourier transform, where the window size is the same for all scales, the wavelet method uses an optimal window size for each scale. The only drawback is that the spatial localization is not good for large-scale wavelets. This results in a decrease in the mapping quality of the Te for thicker plates, compared to thinner plates, as higher Te values correspond to higher transitional wavelengths.

\section{Results}

We computed the Te for the whole Indian shield and the adjoining regions using the isotropic fan wavelet method. To avoid edge effects, we used the land-ocean deconvolution 

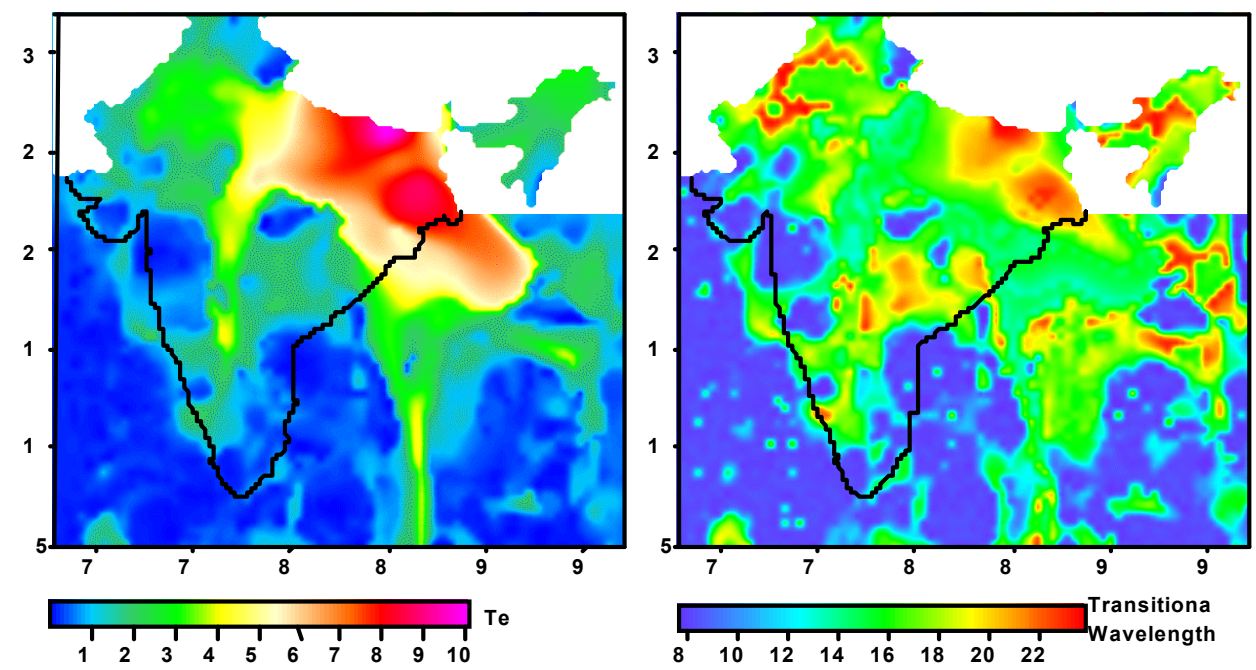

Figure 3. (a) Te map of the Indian shield and the adjoining oceanic regions. (b) Transitional wavelength (km).

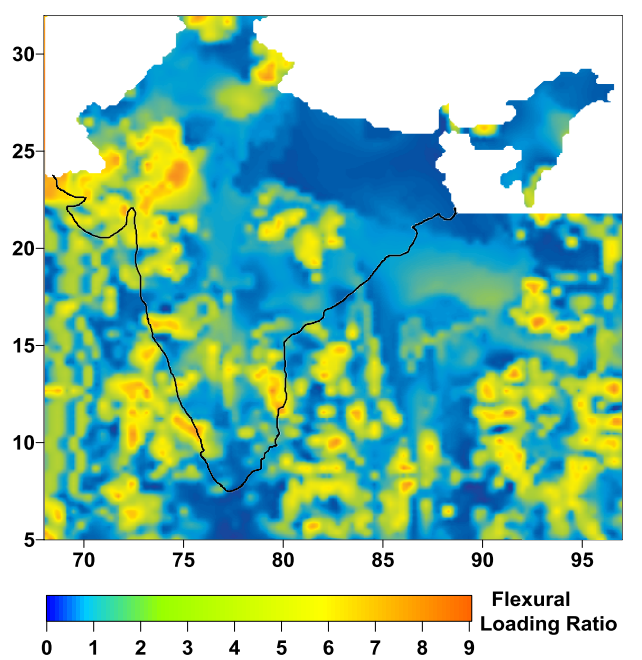

Figure 4. (a) Flexural loading ratio. (b) Error in the estimation of the Te.

technique. As the main aim of this study is to discuss the spatial variations of the Te within the Indian shield and not in the adjoining oceanic regions, we blanked out the portions outside the Indian shield. However to explain the global positioning system velocity vectors in the Nepal Himalaya, we only considered the Te values for that particular region outside India. We ensured that the window size was large enough to capture the flexural signatures. The Te values obtained are quite low for peninsular India $(<50 \mathrm{~km})$, except for the Central Himalayan foreland, where they are $70 \mathrm{~km}$ to $100 \mathrm{~km}$ (Figure 3a). Moreover the geological provinces of the different ages have different Te values i.e., the Archean (0 to $45 \mathrm{~km}$ ), Proterozoic ( 45 to $70 \mathrm{~km}$ ), and Tertiary and Quaternary provinces (70 to $100 \mathrm{~km})$. Thin Te values (0-45 $\mathrm{km}$ ) are unusual for continental regimes of generally low heat flow and other indicators of low temperature, such as old geologic age. The transitional wavelength is shown in Figure $3 \mathrm{~b}$. We also computed the flexural loading ratio (Figure 4a), which shows a value within $0-9$. The error in the estimation of the Te is shown in Figure $4 \mathrm{~b}$. The estimated average errors

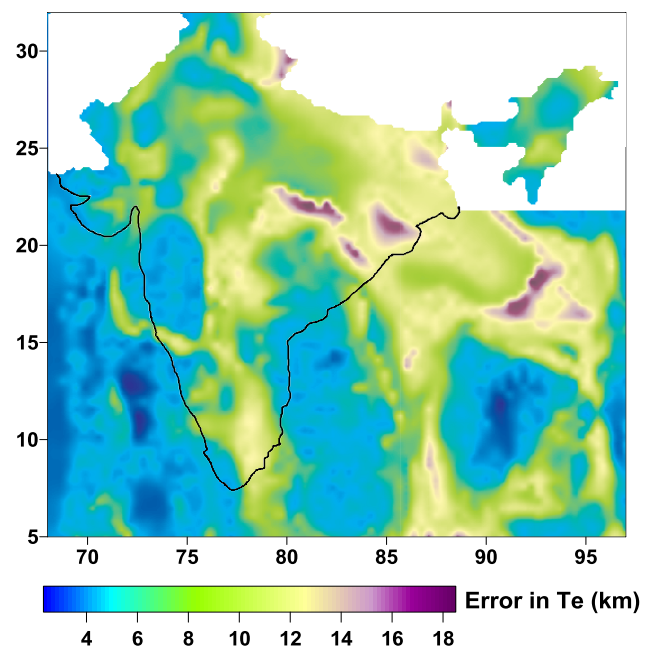

for the Archean, Proterozoic, Tertiary and Quaternary regions are $6 \mathrm{~km}, 8 \mathrm{~km}, 9 \mathrm{~km}$ and $5 \mathrm{~km}$, respectively.

\section{Discussion}

The Te values of continental cratons are normally high $(>60 \mathrm{~km})$. In Table 1, we have listed the results of recent studies of the Te in continental shields. In most cases, the Te is greater than the depth of the crustal thickness, which suggests that the strength resides in the upper mantle as well. Moreover, there is no clear correlation of Te with geological age (Table 1). The correlations between the Te and its controlling factors have always been complex and nonuniform. Although several studies have computed the Te values for the Indian shield, none of these, except Jordan and Watts [2005], captured the spatial variation of the Te. Jordan and Watts [2005] used gravity and flexural modeling, and they reported high values of the Te (80$125 \mathrm{~km}$ ) in the central Himalayan foreland. Our estimated Te values are in good agreement with those of Jordan and Watts [2005]. We found that the Te values within the Indian shield vary for the different geological ages: $0 \mathrm{~km}$ to $45 \mathrm{~km}$ for 


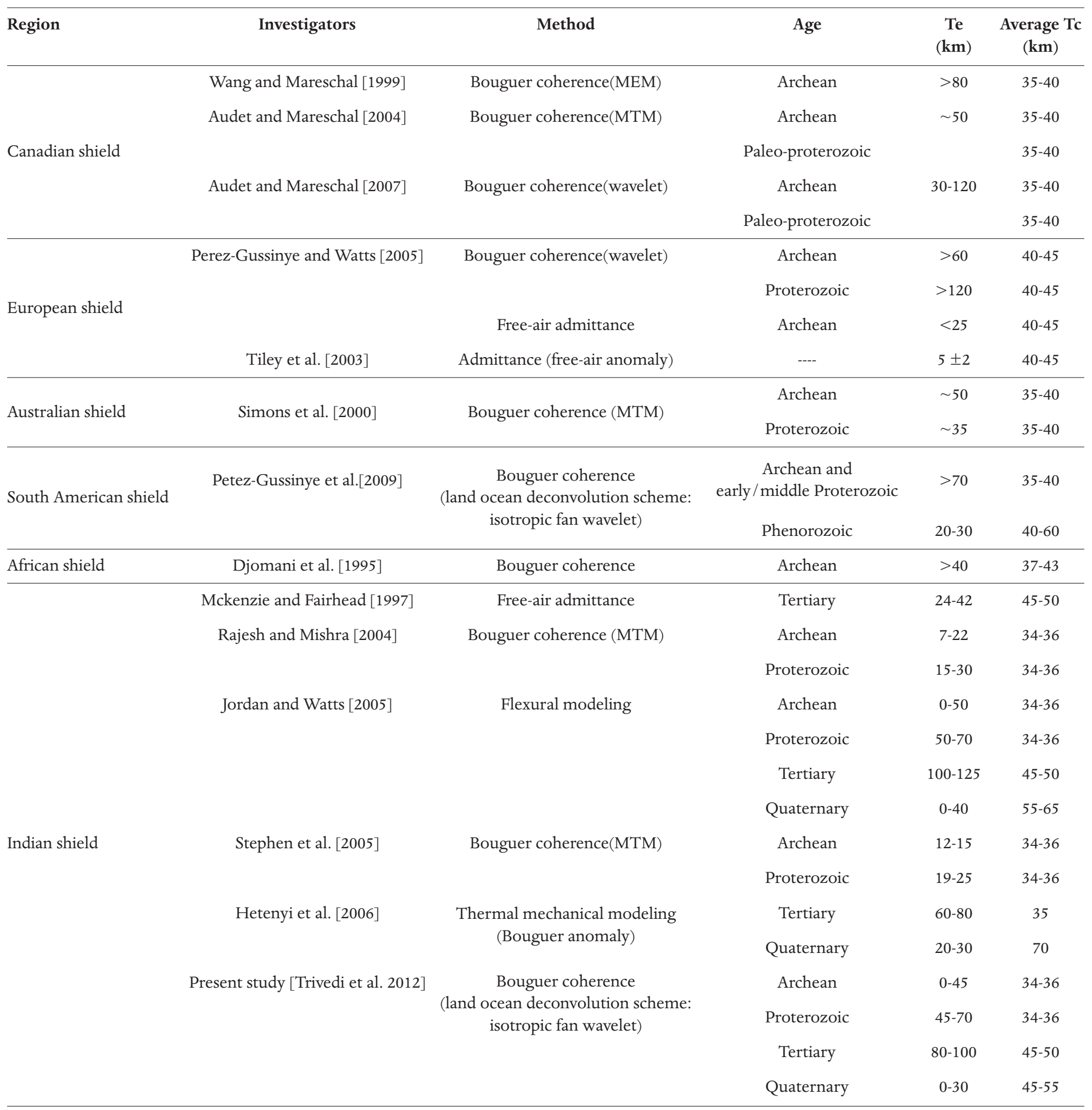

Table 1. Estimation of the elastic thickness (Te) at the continental cratons and the average crustal compensation (Tc).

Archean, $45 \mathrm{~km}$ to $70 \mathrm{~km}$ for Proterozoic, $70 \mathrm{~km}$ to $100 \mathrm{~km}$ for Tertiary, and $0 \mathrm{~km}$ to $35 \mathrm{~km}$ for Quaternary. Our rigidity structure is shown in Figure 5, and it indicates that the older sections of the Indian shield are indeed weaker, with respect to the younger ones. The Te patterns demonstrate a nucleus of variable high strength $(50-100 \mathrm{~km})$ along the north-central part of the Indian shield. In the north-eastern part, the rigidity structure is uniform. The southern shield demarcates a variable low-strength variation $(0-50 \mathrm{~km})$.

The reconstructions of the lithospheric geotherm carried out by Artemieva and Mooney [2001] and Artemieva [2006] showed that the southern Indian shield (chiefly the Archean) is colder than the north Indian region. These above-mentioned results are in contrast to our present estimates of the long-term lithospheric strength using the rheological profiles for the Indian region. Manglik and Singh [1999] showed that the stronger zones are mostly located in southern India, and are characterized by the lowest surface heat flow. Taking into account the above considerations, our present results suggest the possibility of the coupling/ decoupling of the crust-mantle interface that can considerably increase or decrease the elastic strength [Burov and Diament 1995]. This possible causal 

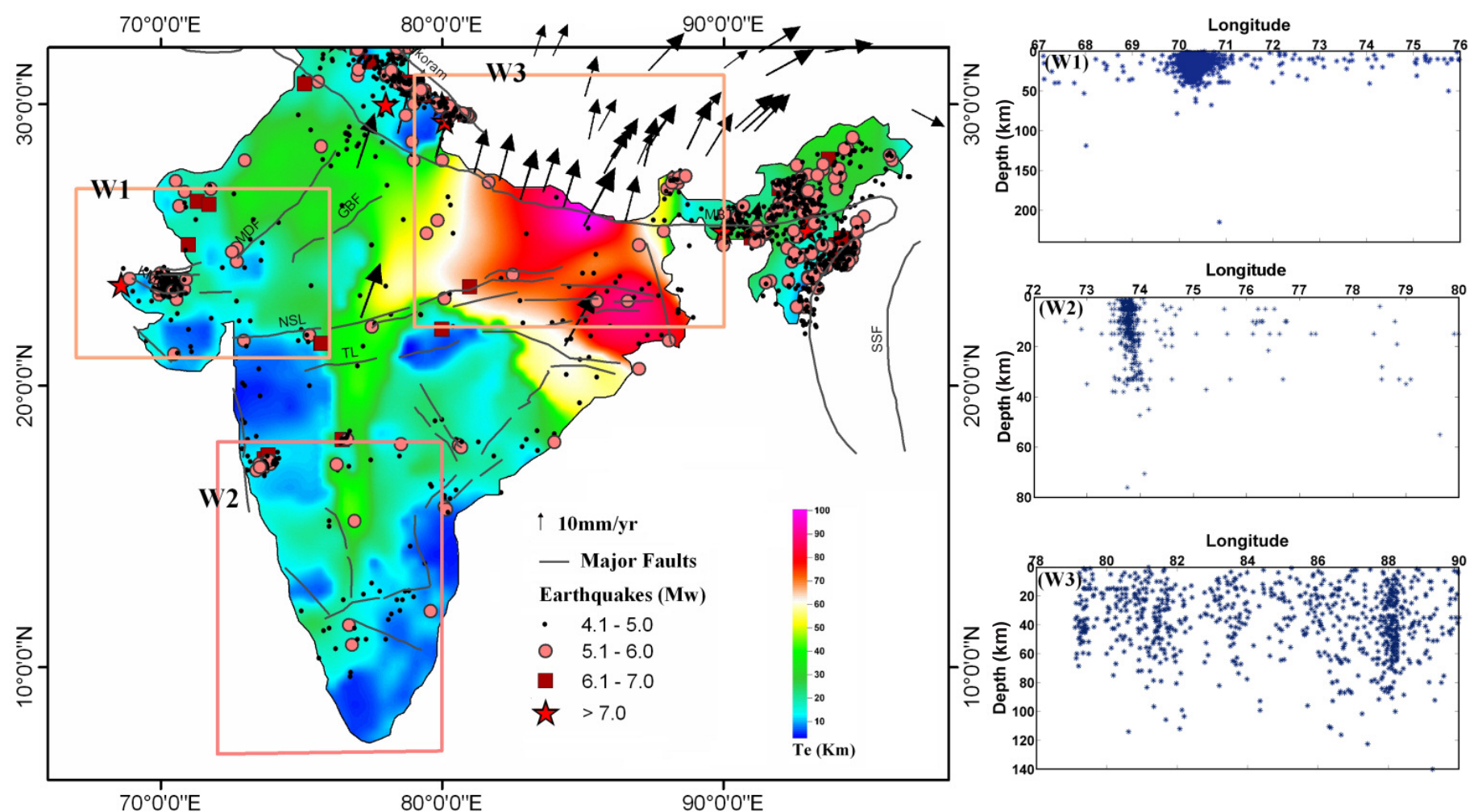

Figure 5. Spatial variation of the Te within the Indian shield shown with the tectonic features in India, with some of the major active faults and lineaments [Dasgupta et al. 2000]. Abbreviations: MDF, Mahendergarh-Dehradun fault; NSL, Narmada Son lineament; TL, Tapti lineament; SSF, Shan-Shagaing fault; MBT, Main Boundary thrust; KMF, Kutch Mainland fault. Epicenters of the different earthquakes with magnitude Mw $\geq 4$ are shown. Their hypocentral depths are projected onto the vertical plane as longitude versus depth for three windows (W1, W2, W3), as shown on the right-hand side. The seismicity of the region was taken from NEIC (http://earthquake.usgs.gov/regional/neic) and GCMT (http://www.globalcmt.org/). The geodetic velocity vectors for the Indian subcontinent are shown with respect to Eurasia (arrows) [Calais et al. 2006, Meade 2007, Thatcher 2007].

relationship needs to be investigated further to improve our understanding of the results obtained for the Indian shield. Burvo and Diamond [1995] provided several pieces of evidence around the globe that suggest that the lower crust of most continental plates has a low temperature activation rheology that can result in crust-mantle decoupling. Our present data show that the decoupling of the crust and the mantle might be one of the important properties that determine the present apparent values of the Te. The decoupling can be attributed to variations in the composition and thickness in the crust, due to a low-temperature-activated lower crust or a thick crust. In contrast, coupling can be due to basic high-temperatureactivated crust with mantle lithosphere. Gupta et al. [2003] used receiver function analysis at several sites of Archean and Proterozoic terrains in south India and they obtained anomalous crustal thicknesses of $42 \mathrm{~km}$ to $51 \mathrm{~km}$ beneath the mid-Archean. These reported high crustal thicknesses favor the possibility of the crust-mantle decoupling mechanism.

To check the plausibility of the Te results thus obtained, we conducted several tests with other approaches, to estimate the Te and the loading ratio simultaneously at each point. These tests ensure that the present Te estimates are real features and not artifacts due to the methodologies used. In the present Fan-wavelet method used, the computation is performed at each grid point of an initial surface and subsurface loads. These tests confirmed that the method is robust and the pattern of the Te variation is realistic and interpretable. The spatial variations in the Te values thus obtained were retrieved using continuous wavelet transform instead of the Fourier approach. The problem of using smaller window sizes in the Fourier approach is thus bypassed by using larger window sizes in our present estimation. Tassara et al. [2007] used a similar approach based on fanwavelet and obtained a causal relationship of rigidity structure with respect to the seismogenic zone along the seduction fault in South America.

The flexural loading ratio (Figure 4a) varies from 0 to 9 . The loading ratio is $<1$ for the region with the high Te values, whereas it has a high value for regions with low $\mathrm{Te}$ values, contrary to the observations of Tassara et al. [2007], who reported a loading ratio $>1$ for the Te $<15 \mathrm{~km}$. This correlation between the $\mathrm{Te}$ and the loading ratio explains the subsurface mass distribution.

The transitional wavelength (Figure $3 \mathrm{~b}$ ) is the wavelength where the coherence between the Bouguer anomaly and the topography changes from high to low, or the coherence approaches the value of 0.5 . Thus, it is a quality check for the estimation of the Te and it is seen to correlate well with our Te values obtained. The transitional wavelength is high (ca. 200-220 km) for the regions with high Te, whereas it is low 
(ca. 75-90 km) for the small pockets with low Te values. The north-south strip that shows a moderate Te value through central India (ca. $45 \mathrm{~km}$ ) also finds its resemblance in the map of the transitional wavelength. The error in calculating the Te values is within acceptable limits (Figure $4 \mathrm{~b}$ ), and hence supports the Te values obtained.

\section{Te versus Ts:}

A seismotectonic map is shown in Figure 5, with the earthquake epicenters and some of the major faults and lineaments shown. In Figure 5, the spatial Te variation is shown, and for three windows (Figure 5, boxes W1, W2 and W3) the hypocenters are projected onto the vertical planes. For windows 1, 2 and 3, the majority of the earthquakes are within $50 \mathrm{~km}, 40 \mathrm{~km}$ and $100 \mathrm{~km}$ in depth, respectably. From the analysis of these windows and their corresponding $\mathrm{Te}$ values, we can see that for windows with greater Te values, this means having more Ts. Hence, from the analysis, we can conclude that Te is proportional to Ts. For windows 1 and 2, most of the events occurred within the Moho. However in window 3, the crust and the upper mantle are seismically active, as subduction is still active. Thus, there is an obvious correlation between $\mathrm{Te}$ and $\mathrm{Ts}(\mathrm{Te} \approx \mathrm{Ts}$ ), except for a few isolated events in these regions. These data agree well with those obtained by McKenzie and Fairhead [1997], who on account of their free-air admittance method, obtained Te $\sim \mathrm{Ts}$ and suggested that the strength of the lithosphere resides in the seismogenic layer only. Maggi et al. [2000] obtained Te $<$ Ts, and therefore suggested that the strength resides in the seismogenic layer, while the lower part of the seismogenic layer does not contribute to the strength. However, Watts and Burov [2003] suggested that $\mathrm{Te}>>\mathrm{Ts}$ for the continental lithosphere, especially in the case of cratons, convergent zones, and rifts. They attributed this result to the multilayer rheology of the continental crust below cratons. From the global positioning system velocity vector in the Himalayan region, Bilham et al. [1997] suggested a locking depth of 20 $\pm 4 \mathrm{~km}$ and aseismic creep beyond that depth. In Figure 5, the geodetic velocity vectors for the India-Eurasia collision zone are shown [Calais et al. 2006, Meade 2007, Thatcher 2007]. One possible interpretation of our data might be that the aseismic part of the Te has the major role in defining the lithospheric strength, whereas the upper seismogenic layer is weak over a geological time scale. This result appears to be quite reasonable if we consider the Ts to be indicative of the frictional instability, which leads to the release of strain energy rather than strength. This also dismisses the concept of a weak mantle in active subduction zones in continental regions.

\section{Conclusions}

Our results infer that the cratonic Te of the Indian shield is significantly lower than the global averages. A north-south high Te is hypothesized, due to the effects of the Indian shield that ploughed into the mantle during its movement. This enhanced travel might be due to the high root strength of the Indian shield. We propose that the perfect coupling and high root strength at the Central Himalayan zone is due to competent rheology with the absence of wet crustal rheology. A large accumulation of stress connected with a network of faults might result in localization of the stress and incompetent layering, with a wet crustal rheology interpreted for the Indian peninsular shield and therefore relatively weak, although a craton. In addition, the presence of a crustal root in the peninsular shield without expression of the topography might have resulted in reduced strength. Although the Indian plate had an eventful tectonic history, including its movement over various hot spots, the present Te structure is suggestive of the dominant signatures of the last major tectonic episode of the formation of the Himalayas, and as a result, of crust-mantle coupling and decoupling. These results also support the inverse correlation between geological age and Te values.

Acknowledgements. We thank DST and INCOIS for the necessary funding. Profs. Swain and Kirby are gratefully acknowledged for providing the software code for the computation. C. S. Vijayalakshmi is thanked for the data preparation.

\section{References}

Andersen, O.B., and P. Knudsen (1998). Global marine gravity field from ERS-1 and GEOSAT geodetic mission altimetry, J. Geophys. Res., 103, 8129-8137.

Andersen, O.B., P. Knudsen, P. Berry, J. Freeman, N. Pavlis and S. Kenyon (2008). The DNSC07 ocean-wide altimetry-derived gravity field, In: EGU Proceedings, Session G1, General Assembly, Vienna, Austria, April 14-18.

Artemieva, I.M., and W.D. Mooney (2001). Thermal structure and evolution of Precambrian lithosphere: a global study, J. Geophys. Res., 106, 16387-16414.

Artemieva, I.M. (2006). Global $1 \times 1$ thermal model TC 1 for the continental lithosphere: implications for lithosphere secular evolution, Tectonophysics, 416, 245-277.

Audet, P., and J.C. Mareschal (2004). Variation in elastic thickness in the Canadian shield, Earth Planet. Sci. Lett., 226, 17-31.

Audet, P., and J.C. Mareschal (2007). Wavelet analysis of the coherence between Bouguer gravity and topography: application to the elastic thickness anisotropy in the Canadian shield, Geophys. J. Int., 168, 287-298; doi:10.1111/ j.1365-246X.2006.03231.x.

Bassin, C., G. Laske and G. Masters (2000) The current limits of resolution for surface wave tomography in North America, EOS Trans. AGU, 81, F897.

Bilham, R., K. Larson, J. Freymueller and Project Ldylhim Members (1997). GPS measurements of present-day convergence across the Nepal Himalaya, Nature, 386 (6620), 61-64.

Bir Singh, I. (1996). Geological evolution of Ganga Plain - 
an overview, J. Paleontological Soc. India, 41, 99-137.

Biswas, S.K. (1999). A review on the evolution of rift basins in India during Gondwana with special reference to western Indian basins and their hydrocarbon prospects, Publ. INSA, 65, A, 3, 261-283.

Burov, E., and M. Diament (1995). The effective elastic thickness of continental lithosphere: What does it really mean?, J. Geophys. Res., 100 (B3), 3905-3927.

Calais, E., L. Dong, M. Wang, Z. Shen, and M. Vergnolle (2006). Continental deformation in Asia from a combined GPS solution, Geophys. Res. Lett., 33, L24319; doi:10.1029/ 2006 GL028433.

Dasgupta, S., P. Pande, D. Ganguly, Z. Iqbal, K. Sanyal, N.V. Venkatraman, S. Dasgupta, B. Sural, L. Harendranath, K. Mazumdar, S. Sanyal, K. Roy, L.K. Das, P.S. Misra and H. Gupta (2000). Seismotectonic Atlas of India and its Environs, Geological survey of India Publication.

Djomani, Y.H.P., J.M. Nnange, M. Diament, C.J. Ebinger and J.D. Fairhead (1995). Effective Te and crustal thickness variations in west central Africa inferred from gravity data, J. Geophys. Res., 100 (B11), 22047-22070.

Gupta, S., S.S. Rai, K.S. Prakasam and D. Srinagesh (2003). The nature of the crust in southern India: Implications for Precambrian crustal evolution, Geophys. Res. Lett., 30 (8), 1419; doi: 10.1029 2002GL016770

Handy, M.R., and J.P. Brun (2003). Seismicity, structure and strength of the continental lithosphere, Earth Planet. Sci. Lett., 223, 427-441.

Hetenyi, G., R. Cattin, J. Vergne and J.L. Nabelek (2006). The effective elastic thickness of the India Plate from receiver function imaging, gravity anomalies and thermomechanical modelling, Geophys. J. Int., 167, 1106-1118; doi:10.1111/j.1365-246X.2006.03198.x.

Jordan, T.A., and A.B. Watts (2005). Gravity anomalies, flexure and the elastic thickness structure of the India-Eurasia collisional system, Earth planet. Sci. Lett., 236, 732-750.

Karner, G.D., and A.B. Watts (1983). Gravity anomalies and flexure of the lithosphere at mountain ranges, J. Geophys. Res., 20, 10449-10477.

Kirby, J.F., and C.J. Swain (2004). Global and local isostatic coherence from the wavelet transform, Geophys. Res. Lett., 31, L24608; doi:10.1029/2004GL021569.

Kirby, J.F., and C.J. Swain (2011). Improving the spatial resolution of effective elastic thickness estimation with the fan wavelet transform, Computers \& Geosciences, 37 (9), 1345-1354.

Krishnan, M.S. (2006). Geology of India and Burma, 6th edition, CBS Publisher, $536 \mathrm{pp}$.

Lyon-Caen, H., and P. Molnar (1985). Gravity anomalies, flexure of the Indian plate, and the structure, support and evolution of the Himalaya and Ganga basin, Tectonics, 4, 513-538.

Maggi, A., J.A. Jackson, D. McKenzie and K. Priestley (2000).
Earthquake focal depths, effective Te, and the strength of the continental lithosphere, Geology, 28 (6), 495-598.

Manglik, A., and R.N. Singh (1999). Rheological stratification in the Indian continental lithosphere: Role of diffusion creep, Proc. Indian Acad. Sci. (Earth Planet. Sci.), 108, 15-21.

McKenzie, D., and J.D. Fairhead (1997). Estimates of the effective Te of the continental lithosphere from Bouguer and free air gravity anomalies, J. Geophys. Res., 102, 27523-27552.

McNutt, M.K., M. Diament and M.G. Kogan (1988). Variations of elastic plate thickness at continental thrust belts, J. Geophys. Res., 93, 8825-8838.

Meade, B.J. (2007). Present-day kinematics at the India-Asia collision zone, Geology, 35, 81-84; doi:10.1130/ G22924A.1

Naqvi, S.M. (2005). Geology and Evolution of the Indian Plate, Capital Publishing Company, New Delhi, 450 pp.

National Oceanic and Atmospheric Administration (2003). General Bathymetric Chart of oceans; http: / / www.ngdc. noaa.gov/mgg/gebco/grid/development.pdf.

Pérez-Gussinyé, M., and A.B. Watts (2005). The long term strength of Europe and its implications for plate-forming processes, Nature, 436, 381-384.

Pérez-Gussinyé, M., C.J. Swain, J.F. Kirby and A.R. Lowry (2009). Spatial variations of the effective elastic thickness, Te, using multitaper spectral estimation and wavelet methods; Examples from synthetic data and application to South America, Geochem. Geophys. Geosyst., 10, Q04005; doi:10.1029/2008GC002229.

Rajesh, R.S., J. Stephen and D.C. Mishra (2003). Isostatic response and anisotropy of the Eastern Himalayan-Tibetan Plateu: a reappraisal using multitaper spectral analysis, Geophys. Res. Lett., 30, 1060-1064.

Rajesh, R.S. (2004). Isostatic response and anisotropy of India and Tibetan lithosphere using multitaper spectral analysis, $\mathrm{PhD}$ Thesis, Osmania University.

Rajesh, R.S., and D.C. Mishra (2004). Lithospheric thickness and mechanical strength of the Indian shield, Earth Planet. Sci. Lett., 225, 319-328.

Sen, G. (2001). Generation of Deccan Trap magmas, Proc. Indian Acad. Sci. (Earth Planet. Sci.), 110, 409-431.

Sharma, R.S. (2009). Cratons of the Indian Shield. In Cratons and Fold Belts of India, Lecture Notes in Earth Sciences 127, Springer-Verlag Berlin Heidelberg, 41-115; doi:10.1007/978-3-642-01459-8_2.

Sheth, H.C. (2007). Plume-related regional prevolcanic uplift in the Deccan Traps: Absence of evidence, evidence of absence, In: G.R. Foulger and D.M. Jurdy (eds.), Plates, plumes, and planetary processes, Geological Society of America Special Paper 430, 785-813; doi:10.1130/2007. 2430(36).

Simons, F.J., M.T. Zuber and J. Korenaga (2000). Isostatic response of the Australian Lithosphere: Estimation of effective Te and anisotropy using Multitaper spectral analysis, 
J. Geophys. Res., 105 (19), 163-184.

Stephen, J., S.B. Singh and D.B. Yedekar (2005). Evidence of elastic strength variation across the Central Indian Tectonic Zone: A support to the Proterozoic collisional tectonics, Current Science, 89, 190-195.

Tassara, A., C. Swain, R. Hackney and J. Kirby (2007). Elastic thickness of South America estimated using wavelets and satellite derived gravity data, Earth Planet. Sci. Lett., 253, 17-36.

Thatcher, W. (2007). Microplate model for the present-day deformation of Tibet, J. Geophys. Res., 112, B01401; doi:10.1029/2005JB004244.

Tiley, R., D. Mckenzie and N. White (2003). The elastic thickness of the British Isles, J. Geol. Soc. London, 160, 499-502.

Wang, Y., and J. Mareschal (1999). Te of the lithosphere in the central Canadian Shield, Geophys. Res. Lett., 26, 3033-3036.

Watts, A.B. (1992). The effective elastic thickness of the lithosphere and the evolution of foreland basins, Basin Res., 4, 169-178.

Watts, A.B., and E. Burov (2003). Lithospheric strength and its relationship to the elastic and seismogenic layer thickness, Earth Planet. Sci. Lett., 213, 113-131.

\section{Data sources}

GCMT, Global Centroid Moment Tensor Project: http: / / www.globalcmt.org/

NEIC, National Earthquake Information Centre, USGS: http: / / earthquake.usgs.gov/ regional/neic

${ }^{\star}$ Corresponding author: Rajesh R. Nair,

IIT Madras, Department of Ocean Engineering, Madras, India; email: rajeshnair@iitm.ac.in. 